\title{
PDGFC, MARK3 and BCL2 Polymorphisms are Associated with Left Ventricular Hypertrophy in Korean Population
}

\author{
Tae-Eun Jeon ${ }^{*}$ and Hyun-Soek Jin ${ }^{\dagger, * *}$ \\ Department of Biomedical Laboratory Science, College of Life and Health Sciences, \\ Hoseo University, Asan, Chungnam 31499, Korea
}

\begin{abstract}
Left ventricular hypertrophy $(\mathrm{LVH})$ refers to the expansion and the enlarged myocardium due to the increased resistance to ejection from the left ventricle to the aorta and/or the periphery, or the long-term burden imposed by the blood increase. Hypertension is a major risk factor that accounts for more than $50 \%$ of the causes of cardiovascular disease. If hypertension endure in the long term, the myocardium responds to abnormal heartbeat in the heart. Therefore, the prevalence of left ventricular hypertrophy also increases. As a result of genome-wide association study (GWAS) analysis for European people, $P D G F C, M A R K 3$, and $B C L 2$ were related to blood pressures. In this study, the genetic polymorphisms of $P D G F C$, $M A R K 3$, and BCL2 were extracted and selected based on Korean genomic and epidemiologic data, and then logistic regression analysis was performed on LVH. As a result, one SNP (rs9307953) in PDGFC gene, four SNPs (rs6575983, rs17679475, rs2273703 and rs10141388) in MARK3 gene and two SNPs (rs17756073 and rs17070739) in BCL2 gene were statistically significant. The rs6575983 of the MARK3 gene showed the highest significance level $\left(P=7.2 \times 10^{-3}\right)$ among the SNPs and the relative risk of 1.08 (95\% confidence interval: 1.06 to 1.45). These results suggest that the polymorphisms of PDGFC, MARK3, and BCL2 not only affect European blood pressures but also correlate with LVH in Korean. These results suggest that increased understanding of the genetic correlations of the pathogenesis of LVH.
\end{abstract}

Key Words: BCL2, Candidate gene association study, Hypertension, Left ventricular hypertrophy, MARK3, PDGFC

서 론

좌심실 비대(Left Ventricular Hypertrophy)는 비정상적인 심부하에 대한 심근의 반응 형태이다. 좌심실에서 대동맥 혹은 말초로의 박출저항이 높아지거나 혈액량 증가로 인 해 장기적인 부담이 가해지면 심근이 늘어나고 확장이 일어나게 된다(Im, 1995; Chung and Song, 2007). 또한 관상 동맥질환, 급사, 심부전 등의 심혈관계 질환에서 독립적 인 위험 요인으로 작용한다. 좌심실 비대를 진단하는 검
사로는 심전도 검사, 심장초음파검사, 단순 흉부 방사선 검사 등이 시행되며, 이 중 심전도 검사가 좌심실 비대 의 선별검사에서 가장 많이 사용되고 있다(Reichek and Devereux, 1981).

고혈압은 우리나라 인구 중 30 세 이상에서 약 $30 \%$ 의 유병률을 나타내는 대표적인 만성질환으로 수축기 혈압 (Systolic Blood Pressure, SBP) 또는 이완기 혈압(Diastolic Blood Pressure, DBP)이 지속적으로 높게 유지되는 상태를 말한다(Ahn, 2007). 최근에는 서구화된 식습관과 스트레스 등으로 인하여 비만인 인구가 증가하고 있다. 이에 따라

Received: July 24, 2019 / Revised: September 11, 2019 / Accepted: September 16, 2019

*Undergraduate student, ${ }^{* *}$ Professor.

† Corresponding author: Hyun-Seok Jin. Department of Biomedical Laboratory Science, College of Life and Health Sciences, Hoseo University, Asan, Chungnam 31499, Korea.

Tel: +82-41-540-9968, Fax: +82-41-540-9997, e-mail: jinhs@hoseo.edu

(C) The Korean Society for Biomedical Laboratory Sciences. All rights reserved.

(c) This is an Open Access article distributed under the terms of the Creative Commons Attribution Non-Commercial License (http://creativecommons.org/licenses/by-nc/3.0/) which permits unrestricted non-commercial use, distribution, and reproduction in any medium, provided the original work is properly cited. 
혈관에 과부하가 지속되면서 고혈압이 유발되고 있다. 고 혈압이 장기적으로 지속될 경우 심장에 비정상적인 심부 하로 인해 심근이 반응하여 좌심실 비대의 유병률 역시 증가된다(Levy et al., 1990; Sullivan et al., 1993; Oh, 1996; Chung and Song, 2007). 고혈압은 심혈관계 질환의 발생 원 인 중 주요 위험요소로, 원인의 약 $50 \%$ 이상을 차지한다 (WHO, 2002). 고혈압의 발생 원인은 혈압에 따라 신장에 서 $\mathrm{Na}^{+}$과 수분의 재흡수를 조절하고 심혈관 기능의 조절 에 관여하는 레닌-안지오텐진-알도스테론 시스템(ReninAngioten-Aldosterone System, RAAS) 및 교감 신경계(Sympathetic Nervous System, SNS)의 장애에 의한 것들이 대표 적으로 알려져 있다(Drummond et al., 2019). 따라서 이러한 고혈압은 유전적 요인과 식습관 및 생활환경 등의 환경적 요인이 복합적으로 작용되어 나타난다.

앞서 보고된 논문(Evangelou et al., 2018)에서는 유럽계 사람들(UK Biobank data: 502,620명, ICBP data: 299,024명) 을 대상으로 혈압과 관련된 특성[SBP, DBP, Pulse Pressure (PP)]에 대해 genome-wide association study (GWAS) 분석 을 하였다. 그 결과 535개의 새로운 유전좌위(gene loci)가 발견되었다. 본 연구에서는 발표된 유전좌위 중 $\mathrm{SBP}, \mathrm{DBP}$, $\mathrm{PP}$ 의 세 가지 항목에서 공통적으로 유의성을 보인 유전 좌위(PDGFC, MARK3, BCL2)를 한국인 유전체 역학 데이 터를 기반으로 각 유전자의 다형성과 좌심실 비대의 상 관관계를 분석하였다.

\section{재료 및 방법}

\section{연구 대상자}

이번 연구를 위한 한국인 연구 대상자는 한국인 유전체 역학 조사 사업(Korean genome and epidemiology; KoGES) 의 일환인 Korean Association Resource (KARE)를 기반으로 하였다(Cho et al., 2009). 연구에 사용된 자료는 질병관리본 부 인체자원은행에서 분양을 받아 사용하였다 $(\mathrm{KBN}-2017-$ 046). 이는 질병관리본부에서 한국인 역학 및 유전체 연 구를 위해 경기도 안성 지역과 안산 지역 거주자들을 대 상으로 한 코호트 연구이다. 대상자는 40세에서 69세 사 이의 10,038 명을 모집하였고, 이 중 QC (Quality Control) 과정을 통해 분석 기준에 적합하지 않은 1,198 명이 제외 되어 8,840 명(남성: 4,182 명, 여성: 4,658명)을 분석에 가능 한 연구 대상자로 선정하였다. 이번 연구는 좌심실 비대 에 대한 유전 변이와의 상관성 연구가 목적이므로 8,840 명 의 대상자 중에서 심전도 검사를 하지 않은 대상자를 제
외하여 최종적으로 8,828 명을 연구 대상으로 선정한 후, 좌심실 비대 환자와 건강 대조군을 선별하였다. 좌심실 비대 환자군으로는 심전도 검사에서 좌심실 비대의 진단 기준에 해당하는 1,274 명을 선정하였고, 건강 대조군으로 는 7,581명 중 특별한 질환이 없는 2,772 명을 선정하였다. 좌심실 비대 환자군과 건강 대조군의 평균 나이는 각각 $54.41 \pm 9.08$ 세와 $50.66 \pm 8.70$ 세로 두 그룹 사이에 유 의한 차이가 있었다. 이번 연구에 활용한 유전 정보는 질 병관리본부(KNIH, National Institutes of Health)와 호서대 학교에서 연구 윤리 승인을 받은 후 분석을 진행하였다 (1041231-170822-BR-062-01).

\section{좌심실 비대 진단 기준}

좌심실 비대는 Minnesota Code Classification 시스템에 기초한 심전도 결과를 기반으로 진단되었으며, 진단 기준 은 R 진폭이 V5, V6에서 $26.0 \mathrm{~mm}$ 를 초과하거나 I, II, III, $\mathrm{aVL}$ 유도에서 $20.0 \mathrm{~mm}$ 를 초과하거나 혹은 $\mathrm{aVL}$ 유도에 서 $12.0 \mathrm{~mm}$ 를 초과했을 경우에 좌심실 비대로 판단하였 다(Tuinstra et al., 1982). 또한 만약 이가 나타나지 않은 경 우에는 I 유도에서 $\mathrm{R}$ 진폭이 전체적으로 $15.0 \mathrm{~mm}$ 를 초과 하지만 $20.0 \mathrm{~mm}$ 이하이거나 혹은 V5 또는 V6에서의 R 진폭과 $\mathrm{V} 1$ 에서의 $\mathrm{S}$ 진폭이 $35.0 \mathrm{~mm}$ 를 초과하는 대상자 를 좌심실 비대로 진단하였다.

\section{유전형 분석과 Single Nucleotide Polymorphism (SNP) 선별}

이번 연구에서는 KARE 유전형 자료를 기반으로 SNP 을 선별하였다. DNA 시료는 연구 참여자의 말초 혈액에 서 분리 추출하였고, 유전형 판독을 위해서는 Affymetrix Genome-Wide human SNP array 5.0 (Affymetrix, Inc., Santa Clara CA, USA)을 사용하였다. 유전형 판독 정확도가 $98 \%$ 이하이거나, $4 \%$ 이상의 높은 missing genotype call rate을 보이거나, $30 \%$ 초과의 heterozygosity를 가지거나, 성별 불 일치가 존재하는 대상자들은 제외되었고 또한 암을 갖 고 있던 대상자들도 제외되었다. 이번 연구에서 분석한 $P D G F C, M A R K 3, B C L 2$ 유전자들의 영역은 각각의 전사 체 $(209,783 \mathrm{bp}, 118,466 \mathrm{bp}, 196,035 \mathrm{bp})$ 양 말단에서 $5 \mathrm{~kb}$ 씩 확장하여 이 범위에 존재하는 각각 15 개, 18 개, 35 개의 $\mathrm{SNP}$ 들을 대상으로 하였다. 이 $\mathrm{SNP}$ 들의 염색체 상의 위 치는 UCSC Genome Browser on Human Mar. 2006 (NCBI human genome build 36)을 기준으로 하였다. 


\section{상관성 분석과 통계 분석}

대부분의 통계 분석에는 PLINK version 1.07 (http://pngu.mgh.harvard.edu/ purcell/plink)과 PASW Statistics version 18.0 (SPSS Inc. Chicago, IL, USA)을 사용하였다. 좌심실 비대 환 자군과 건강 대조군에 대한 유전적 변이의 상관성 분석은 로지스틱 회귀 분석을 사용하였으며 additive genetic model 을 기반으로 하였다. 회귀 분석 시행 시 공변수에 나이, 지역, 성별을 처리하여 분석하였고, 분석값에 대한 유의 수준은 0.05 이하를 기준으로 하였다. Regional association plots을 확인하기 위하여 웹 기반 프로그램인 Locuszoom version 1.1 (http://csg.sph.umich.edu/locuszoom)을 사용하였다.

\section{결 과}

\section{$P D G F C, M A R K 3, B C L 2$ 유전자와 좌심실 비대와의 로 지스틱 회귀 분석}

연구 대상자들에 대한 임상 표현형 특징은 Table 1에 정리하였다. 좌심실 비대 환자 $(\mathrm{n}=1,247)$ 의 평균 나이, 성 별 비율은 각각 $50.66 \pm 8.70$, 남성 $63 \%$ 와 여성 $37 \%$ 로
나타났다. 성별 비율은 좌심실 비대 환자군에서 남성의 비율은 $63 \%$ 로 건강 대조군의 남성이 비율인 $48 \%$ 에 비해 서 더 많은 비중을 차지하였다.

이번 연구 대상인 $P D G F C, M A R K 3, B C L 2$ 유전자들은 UCSC Genome Browser on Human Mar. 2006 (NCBI human genome build 36)을 기준으로 각 유전자의 전사체 양 말단 에서 $5 \mathrm{~kb}$ 씩 확장하여 유전자 영역을 설정한 후, $\mathrm{KARE}$ 유전형 정보에서 $\mathrm{SNP}$ 들을 선별하였다. 그 결과 $P D G F C$ 유전자의 분석 대상 $\mathrm{SNP}$ 들은 4 번 염색체에서 15 개의 $\mathrm{SNP}$ 이 확인되었으며, MARK3 유전자는 14 번 염색체에서 18 개의 SNP이 확인되었고, $B C L 2$ 유전자는 18 번 염색체 에서 35 개의 SNP이 확인되었다(Supplementary Table 1). 선 별된 SNP을 대상으로 좌심실 비대 환자군과 건강 대조군 에 대해서 로지스틱 회귀 분석을 시행한 결과 $P D G F C$ 유 전자에서는 1 개의 SNP (rs9307953), MARK3 유전자에서는 4개의 SNP (rs6575983, rs17679475, rs2273703, rs10141388), $B C L 2$ 유전자에서는 2개의 SNP (rs17756073, rs17070739)에 서 통계적으로 유의한 상관관계 $(P<0.05)$ 를 확인할 수 있 었다. 이 중 MARK3 유전자의 rs6575983에서 가장 높은 유의 수준 $\left(P=7.2 \times 10^{-3}\right)$ 이 나타났으며, 상대적 위험도는

Table 1. Basic characteristics of the subjects in the KARE

\begin{tabular}{lcccc}
\hline \hline \multirow{2}{*}{ Characteristics } & Total & \multicolumn{2}{c}{ LVH } & $P$ value \\
\cline { 3 - 4 } & & 8,840 & 1,247 & 2,772 \\
Number of subjects & $52.22 \pm 8.91$ & $54.41 \pm 9.08$ & $50.66 \pm 8.70$ & 0.002 \\
Age (M years \pm SD) & $4,182(47) / 4,658(53)$ & $790(63) / 457(37)$ & $1,332(48) / 1,440(52)$ & $<0.0001$ \\
Gender [men $(\%) /$ women $(\%)]$ &
\end{tabular}

Abbreviations: KARE, Korean association resource; $M$, mean value; SD, standard deviation

Table 2. Results of the case-control association analysis between SNPs in the PDGFC, MARK3, BCL2 genes and left ventricular hypertrophy in the KARE (Additive $P$ value $<0.05$ )

\begin{tabular}{|c|c|c|c|c|c|c|c|c|c|}
\hline \multirow{2}{*}{ No. } & \multirow{2}{*}{ Gene } & \multirow{2}{*}{$\mathrm{Chr}$} & \multirow{2}{*}{ SNP } & \multirow{2}{*}{ Function } & \multirow{2}{*}{$\mathrm{A} 1$} & \multicolumn{2}{|c|}{ MAF } & \multirow{2}{*}{ OR $(95 \% \mathrm{CI})$} & \multirow{2}{*}{$\begin{array}{l}\text { Additive } \\
P \text { value }\end{array}$} \\
\hline & & & & & & Cases & Controls & & \\
\hline 1 & $P D G F C$ & 4 & rs9307953 & Intron & $\mathrm{T}$ & 0.271 & 0.251 & $1.12(1.00 \sim 1.25)$ & 0.050 \\
\hline 2 & \multirow{4}{*}{ MARK3 } & \multirow{4}{*}{14} & rs6575983 & Upstream & $\mathrm{G}$ & 0.116 & 0.096 & $1.24(1.06 \sim 1.45)$ & $7.2 \times 10^{-3}$ \\
\hline 3 & & & rs17679475 & Intron & G & 0.122 & 0.103 & $1.21(1.04 \sim 1.41)$ & 0.016 \\
\hline 4 & & & rs2273703 & Intron & $\mathrm{G}$ & 0.122 & 0.103 & $1.21(1.04 \sim 1.41)$ & 0.015 \\
\hline 5 & & & rs10141388 & Intron & $\mathrm{G}$ & 0.120 & 0.102 & $1.21(1.04 \sim 1.41)$ & 0.015 \\
\hline 6 & \multirow{2}{*}{$B C L 2$} & \multirow{2}{*}{18} & rs 17756073 & Intron & $\mathrm{G}$ & 0.116 & 0.135 & $0.84(0.72 \sim 0.98)$ & 0.022 \\
\hline 7 & & & rs 17070739 & Intron & $\mathrm{G}$ & 0.132 & 0.156 & $0.84(0.73 \sim 0.96)$ & 0.012 \\
\hline
\end{tabular}

Abbreviations: SNP, single nucleotide polymorphism; A1, minor allele; MAF, minor allele frequency; OR, odds ration; CI, confidence interval; KARE, Korean association resource 
Table 3. Results of the Regulome DB and HaploReg of SNPs in the PDGFC, MARK3, BCL2 gene

\begin{tabular}{|c|c|c|c|c|c|c|c|c|c|c|c|c|}
\hline \multirow[b]{2}{*}{ Gene } & \multirow[b]{2}{*}{ Chr } & \multirow[b]{2}{*}{ SNP } & \multirow[b]{2}{*}{ A1 } & \multirow[b]{2}{*}{$\mathrm{A} 2$} & \multicolumn{5}{|c|}{ Regulome DB } & \multicolumn{3}{|c|}{ HaploReg } \\
\hline & & & & & Score & TFBS & DNase & $\begin{array}{c}\text { Proteins } \\
\text { bound }\end{array}$ & Motifs & $\begin{array}{c}\text { Promoter } \\
\text { histone } \\
\text { marks }\end{array}$ & $\begin{array}{l}\text { Enhancer } \\
\text { histone } \\
\text { marks }\end{array}$ & Motifs \\
\hline$P D G F C$ & 4 & rs9307953 & $\mathrm{T}$ & A & 6 & - & - & - & $\begin{array}{l}\text { Myogenin/ } \\
\text { NF-1 }\end{array}$ & - & 5 tissues & $\begin{array}{c}4 \text { altered } \\
\text { motifs }\end{array}$ \\
\hline \multirow{4}{*}{$M A R K 3$} & \multirow{4}{*}{14} & rs6575983 & G & $\mathrm{C}$ & 6 & - & - & - & - & - & 17 tissues & Pax-5 \\
\hline & & rs17679475 & G & A & $1 \mathrm{f}$ & - & + & - & - & FAT & 8 tissues & - \\
\hline & & rs2273703 & G & $\mathrm{C}$ & $1 \mathrm{f}$ & - & + & - & - & - & 4 tissues & $\begin{array}{l}7 \text { altered } \\
\text { motifs }\end{array}$ \\
\hline & & rs10141388 & G & A & 5 & + & - & $\begin{array}{l}\text { NFIC, } \\
\text { FOXM1 }\end{array}$ & HOXA13 & - & - & $\begin{array}{l}\text { AIRE, } \\
\text { CTCF }\end{array}$ \\
\hline \multirow{2}{*}{$B C L 2$} & \multirow{2}{*}{18} & rs 17756073 & G & A & 4 & + & + & $\begin{array}{l}\text { GATA2, } \\
\text { GATA3 }\end{array}$ & - & BLD, GI & 12 tissues & - \\
\hline & & rs 17070739 & G & $\mathrm{T}$ & $3 a$ & + & + & RUNX3 & $\begin{array}{l}\text { Sox12, } \\
\text { BCL6B }\end{array}$ & BLD & 7 tissues & ATF3 \\
\hline
\end{tabular}

Abbreviations: SNP, single nucleotide polymorphism; A1, minor allele; A2, major allele; TFBS, transcription binding factor site; +, affect; Regulome DB is a database that annotates SNPs with known and predicted regulatory elements in the intergenic regions of the $H$. sapiens genome (http://www.regulomedb.org/index); HaploReg is a tool for exploring annotations of candidate regulatory SNPs (http://archive.broadinstitute.org/mammals/haploreg/haploreg_v3.php).

1.24(95\% 신뢰구간: 1.06 1.45)로 나타났다. 그러나 BCL2 유전자 SNP 중 유의한 2개의 SNP (rs17756073, rs17070739) 는 상대적 위험도가 두 SNP 모두 0.84로 확인되었으며, 이는 Minor allele $(\mathrm{G})$ 를 가질수록 좌심실 비대 발생의 상 대적 위험도를 감소시키는 방향으로 상관성이 있었다 (Table 2).

\section{$P D G F C, M A R K 3, B C L 2$ 유전자의 유의한 SNP에 대한 in silico 기능 분석}

$P D G F C, M A R K 3, B C L 2$ 유전자에서 통계적으로 유의성 을 가진 총 7 개의 SNP들이 유전자 혹은 단백질 발현에 어떻게 영향을 미치는지 확인하기 위해서 Regulome DB (http://www.reguloumdb.org/index)와 HaploReg (http://archive.broadinstitute.org/mammals/haploreg/haploreg_v3.php)를 이용 하여 in silico 기능 분석을 하였다. 그 결과 MARK3 유전 자의 SNP 중 2개의 SNP (rs17679475, rs2273703)에서 1f score의 의미 있는 score (score<3a)가 나타났다(Table 3). If score는 $\mathrm{eQTL}$ 뿐 만 아니라 해당 $\mathrm{SNP}$ 이 전사 인자 결합 반응에 영향을 미칠 수 있거나 DNase peak에서 차이가 있다는 것을 의미한다. 또한 rs2273703은 HaploReg에서 motif의 변화를 예측하고 있으므로 유전형에 따라 MARK3 유전자 발현에 영향을 미칠 가능성이 있다는 것을 보여 준다.

\section{$P D G F C, M A R K 3, B C L 2$ 유전자의 Regional plot 확인}

$P D G F C, M A R K 3, B C L 2$ 유전자 $\mathrm{SNP}$ 과 좌심실 비대 환 자군 사이의 상관관계를 기반으로 LocusZoom Version 1.1 (http://csg.sph.umich.edu/locuszoom), (Pruim et al., 2010) 프로 그램을 사용하여 regional plot을 확인하였다. 분석 시에는 기준을 hg 19 version ASN (Asian population)으로 하였다. 상관 분석 결과 가장 높은 유의 수준을 나타낸 $\mathrm{SNP}$ 은 자 주색의 다이아몬드로 표시되고, 이는 regional plot의 기준 $\mathrm{SNP}$ 이 된다(Fig. 1). MARK3 유전자의 분석 결과 $\mathrm{r} 65575983$ 을 기준으로 하였을 때 3 개의 SNP에서 $r^{2}>0.8$ 이상으로 나타났다. 따라서 rs6575983과 주위에 있는 유의 수준을 갖는 MARK3 유전자의 SNP들은 서로 연관되어 있다는 것을 확인할 수 있었다.

\section{고 찰}

선행된 논문(Evangelou et al., 2018)에서는 UKB (UK Biobank)와 ICBP (International Consortium of Blood Pressure Genome-wide Association Studies)로부터 얻은 유럽계 사람 들의 혈압과 관련된 특성(SBP, DBP, PP)에 대해 GWAS 분석을 하였다. 그 결과 535 개의 새로운 유전좌위를 발견 하였으며, 이 중 $\mathrm{SBP}, \mathrm{DBP}, \mathrm{PP}$ 의 세 가지 항목과 모두 관 
a

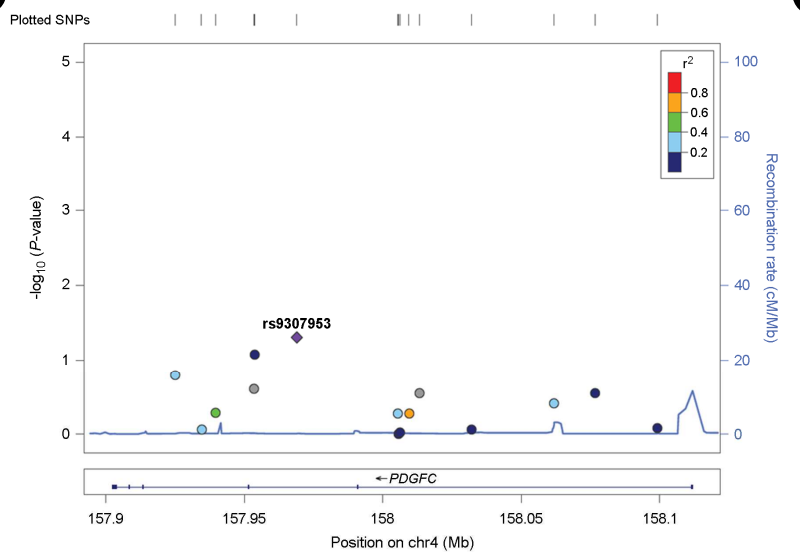

C

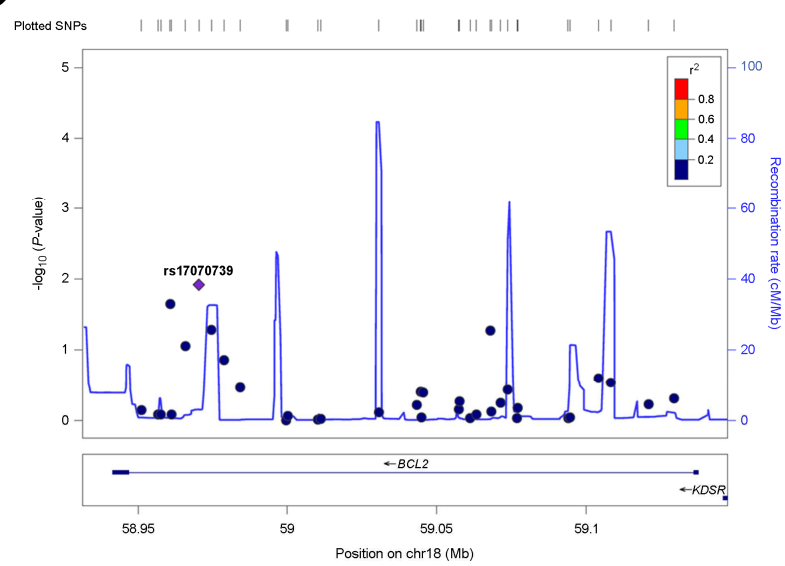

b

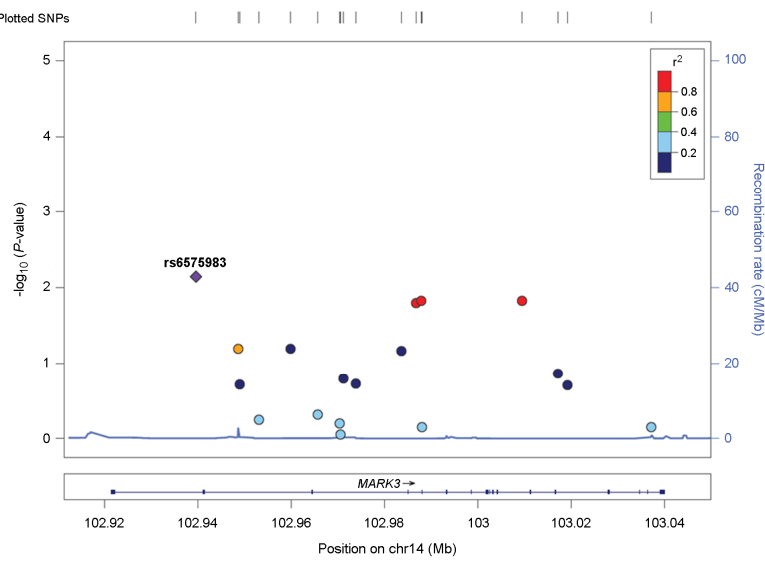

Fig. 1. The results of associations between PDGFC, MARK3, BCL2 SNPs and Left ventricular hypertrophy in KARE. The Figure 1-a shows the association results of the genetic variation on $P D G F C, 1-\mathrm{b}$ shows those of the $M A R K 3$ and 1-c shows those of the BCL2. The statistical significances (- $\log _{10} P$-value) of association with the SNPs are plotted. At the bottom of the figure, the nucleotide positions within the chromosomes where each gene locus matches appears. The recombination rates estimated using HapMap Asian population data is shown by a blue line. The purple diamond with a SNP number represents the SNP most strongly associated with left ventricular hypertrophy, and its correlations with other SNPs are shown by colors indicating the levels of linkage disequilibrium $\left(r^{2}\right)$.
련된 유전좌위는 총 12 개(BCL2, KLF14, L2HGDH, LRP4, MARK3, PDGFC, RXFP2, TERT, ARMC4, FGFR2, SNRNP70, $Y T H D F 3)$ 였다.

고혈압이 오래 지속되는 경우 심장에 비정상적인 심부 하로 인해 심근이 반응하여 좌심실 비대의 유병률 역시 증가되므로 고혈압과 좌심실 비대는 서로 연관성이 있다 고 볼 수 있다(WHO, 2002; Chung and Song, 2007). 그러므 로 이번 연구는 유럽인에서 혈압과 연관성 있다고 새롭 게 발견된 12 개의 유전좌위를 가지고 한국인을 대상으로 유전자의 변이와 좌심실 비대에 대한 상관 분석을 시행 하여 각 유전자의 유전적 다형성이 좌심실 비대에 영향 을 미칠 가능성이 있는지 확인하고자 하였다. 따라서 각 각의 유전자에서 로지스틱 회귀 분석을 통해 좌심실 비대 환자군과 건강 대조군 간의 SNP에 따른 통계적 유의성 을 분석하여 유전적 변이에 따른 좌심실 비대 발생과의 상관성에 대하여 확인해 보았다. 그 결과 $P D G F C$ 유전자
에서 1 개의 SNP (rs9307953), MARK3 유전자에서 4개의 SNP (rs6575983, rs17679475, rs2273703, rs10141388), BCL2 유전자에서 2개의 SNP (rs17756073, rs17070739)들이 좌심 실 비대와 유의한 상관관계 $(P<0.05)$ 를 나타냈다.

Regulome DB와 HaploReg를 이용하여 $\mathrm{SNP}$ 이 유전자 조절이나 단백질 발현에 어떻게 영향을 미치는지 조사 하였다. 그 결과 MARK3 유전자의 $\mathrm{SNP}$ 중 $\mathrm{rs} 17679475$ 와 rs2273703은 Regulome DB score 1f를 나타냈다. 이는 minor allele를 보유함에 따라 MARK3 유전자의 발현에 차이를 나타내는 expression quantitative trait loci (eQTL) 영역임을 의미한다. rs17679475에서는 피하지방, 췌장, 뇌하수체, 전 립선, 혈관 등의 17 개 조직에서 유전자 발현에 차이가 있음을 확인하였다. rs2273703에서는 피하지방, 정강신경, 췌장, 뇌하수체, 혈액 등 16 개 조직에서 유전자의 발현 차이가 나타나는 것을 확인하였다. 또한 rs17679475와 rs2273703은 DNase peak에서 차이가 있음을 확인하였다. 
DNase는 염색질의 특정 영역을 활성화시켜 DNA를 노출 시킨다. 전사 단계에 필요한 여러 인자들은 노출된 DNA에 결합할 수 있게 되고 전사가 이루어진다. 결국 rs17679475, rs2273703은 DNase의 sensitivity를 변화시켜 MARK3 유전 자 전사 활성에 영향을 미칠 것으로 예상한다. $P D G F C$ 유전자의 rs9307953은 myogenin/NF-1 motif를 형성하고 $M A R K 3$ 유전자의 rs10141388은 HOXA13 motif를, BCL2 유전자의 rs17070739는 Sox12와 BCL6B motif를 형성한다. 따라서 각각의 $\mathrm{SNP}$ 들은 유전자 발현에 영향을 미칠 가능 성을 보여주고 있다.

$\mathrm{PDGF}$ 는 혈관의 발달과 동맥 경화증의 발병에 관여한다 (Ross, 1993; Betsholtz and Raines, 1997). PDGFC와 PDGFD 는 $P D G F$ 유전자 군에 속하며, $\mathrm{PDGF}-\mathrm{C}$ 는 민무늬근 세포 에서 발현되고, PDGF-D는 섬유모세포의 외막세포에서 대 부분 발현되어 진다. 두 유전자는 배양된 내피세포 및 다 양한 종양 세포주에서 활성을 보이는 것으로 보고되었다. PDGF-C와 PDGF-D는 사람의 관상동맥 민무늬근 세포를 자극하며(Uutela et al., 2001), PDGFC와 PDGFD가 심장에서 과발현 될 때, $\mathrm{PDGF}-\mathrm{C}$ 는 심근의 섬유아세포 증식을 증가 시키는 것으로 나타났다(Li et al., 2000).

$M A R K 3$ 의 기능은 아직 밝혀지지 않았으나, $M A R K s$ 와 상동관계가 있는 것으로 밝혀졌다(Ono et al., 1997). MARKs 는 미세소관과 관련된 tau 단백질, MAP2 및 MAP4의 특 이적 인산화에 관여하는 새로운 키나아제이며, 결과적으 로 in vitro 및 배양된 세포에서 미세소관으로부터의 분리 를 촉매한다(Drewes et al., 1997).

$B C L 2$ 의 발현은 미토콘드리아에서 나오는 사이토크롬 $\mathrm{C}$ 의 방출을 억제시키고 Apaf-1 complex의 생성을 방해하 므로 세포의 죽음을 예방할 수 있다(Yang et al., 1997). 따 라서 고혈압과 같은 병태생리학적 상태에서 세포자멸사 가 증가하는 현상은 $B C L 2$ 발현이 억제되는 것과 관계가 있다고 한다(Yang et al., 1997; Lee et al., 2006). 따라서 세 포자멸사를 억제시키는 작용을 가진 단백질의 증가는 심 근을 손상으로부터 보호하는 효과를 가지고 있다고 한다 (Fehrenbach and Northoff, 2001).

이번 연구는 대규모 유전체 역학 코호트를 이용한 연 구로서 $P D G F C, M A R K 3, B C L 2$ 유전자의 특정 $\mathrm{SNP}$ 들이 좌심실 비대에 영향을 미칠 수 있을 것이라는 가능성을 제시해주고 있으나 in silico를 통해 진행한 분석이므로 결 과를 간접적으로 확인할 수 있는 한계점이 있다. 현재까 지 여러 질병들의 발생과 환경적 요인 및 유전적 요인과 의 상관관계에 대한 다양한 연구들이 진행되었다(Jin et al., 2018; Ko and Jin, 2019). 이번 연구는 좌심실 비대에 대 해서 한국인의 유전체 역학 자료를 기반으로 분석하였을 때 $P D G F C, M A R K 3, B C L 2$ 유전자 변이들이 좌심실 비대 와의 상관관계가 성립되는지 확인하고자 하였다. 연구 결 과를 통해 $P D G F C, M A R K 3, B C L 2$ 유전자는 유럽인의 혈 압에 영향을 미칠 뿐 만 아니라 한국인에서 좌심실 비대 에도 영향을 미치는 유전자임을 유추할 수 있다.

\section{ACKNOWLEDGEMENT}

This research was supported by Basic Science Research Program through the National Research Foundation of Korea (NRF) grant (NRF-2017R1D1A3B03034752) funded by the Ministry of Education. This study was conducted with bioresources from National Biobank of Korea, the Centers for Disease Control and Prevention, Republic of Korea (KBN2017-046).

\section{CONFLICT OF INTEREST}

The authors declare that they have no competing interests.

\section{REFERENCES}

Ahn YH. Characteristics of subgroups on patients with hypertension for hypertension management -based on knowledge, attitudes, and behavior related to medication and health lifesytle. Korean Academy of Community Health Nursing. 2007. 18: 112-122.

Betsholtz C, Raines EW. Platelet-derived growth factor: a key regulator of connective tissue cells in embryogenesis and pathogenesis. Kidney International. 1997. 51: 1361-1369.

Cho YS, Go MJ, Kim YJ, Heo JY, Oh JH, Ban HJ, Yoon D, Lee MH, Kim DJ, Park M, Cha SH, Kim JW, Han BG, Min H, Ahn Y, Park MS, Han HR, Jang HY, Cho EY, Lee JE, Cho NH, Shin C, Park T, Park JW, Lee JK, Cardon L, Clarke G, McCarthy MI, Lee JY, Lee JK, Oh B, Kim HL. A large-scale genome-wide association study of asian populations uncovers genetic factors influencing eight quantitative traits. Nature Genetics. 2009. 41: 527-534.

Chung JH, Song CH. Factors associated with left ventricular hypertrophy on ECG in middle-aged normotensive healthy men. Korean Journal of Family Medicine. 2007. 28: 92-99.

Drewes G, Ebneth A, Preuss U, Mandelkow EM, Mandelkow E. MARK, a novel family of protein kinases that phosphorylate microtubule-associated proteins and trigger microtubule dis- 
ruption. Cell. 1997. 89: 297-308.

Drummond GR, Vinh A, Guzik TJ, Sobey CG. Immune mechanisms of hypertension. Nat Rev Immunol. 2019. 19: 517-532.

Evangelou E, Warren HR, Mosen-Ansorena D, Mifsud B, Pazoki R, Gao H, Ntritsos G, Dimou N, Cabrera CP, Karaman I, Ng FL, Evangelou M, Witkowska K, Tzanis E, Hellwege JN, Giri A, Velez Edwards DR, Sun YV, Cho K, Gaziano JM, Wilson PWF, Tsao PS, Kovesdy CP, Esko T, Mägi R, Milani L, Almgren P, Boutin T, Debette S, Ding J, Giulianini F, Holliday EG, Jackson AU, Li-Gao R, Lin WY, Luan J, Mangino M, Oldmeadow C, Prins BP, Qian Y, Sargurupremraj M, Shah N, Surendran P, Thériault S, Verweij N, Willems SM, Zhao JH, Amouyel P, Connell J, de Mutsert R, Doney ASF, Farrall M, Menni C, Morris AD, Noordam R, Paré G, Poulter NR, Shields DC, Stanton A, Thom S, Abecasis G, Amin N, Arking DE, Ayers KL, Barbieri CM, Batini C, Bis JC, Blake T, Bochud M, Boehnke M, Boerwinkle E, Boomsma DI, Bottinger EP, Braund PS, Brumat M, Campbell A, Campbell H, Chakravarti A, Chambers JC, Chauhan G, Ciullo M, Cocca M, Collins F, Cordell HJ, Davies G, de Borst MH, de Geus EJ, Deary IJ, Deelen J, Del Greco MF, Demirkale CY, Dörr M, Ehret GB, Elosua R, Enroth S, Erzurumluoglu AM, Ferreira T, Frånberg M, Franco OH, Gandin I, Gasparini P, Giedraitis V, Gieger C, Girotto G, Goel A, Gow AJ, Gudnason V, Guo X, Gyllensten U, Hamsten A, Harris TB, Harris SE, Hartman CA, Havulinna AS, Hicks AA, Hofer E, Hofman A, Hottenga JJ, Huffman JE, Hwang SJ, Ingelsson E, James A, Jansen R, Jarvelin MR, Joehanes R, Johansson Å, Johnson AD, Joshi PK, Jousilahti P, Jukema JW, Jula A, Kähönen M, Kathiresan S, Keavney BD, Khaw KT, Knekt P, Knight J, Kolcic I, Kooner JS, Koskinen S, Kristiansson K, Kutalik Z, Laan M, Larson M, Launer LJ, Lehne B, Lehtimäki T, Liewald DCM, Lin L, Lind L, Lindgren CM, Liu Y, Loos RJF, Lopez LM, Lu Y, Lyytikäinen LP, Mahajan A, Mamasoula C, Marrugat J, Marten J, Milaneschi Y, Morgan A, Morris AP, Morrison AC, Munson PJ, Nalls MA, Nandakumar P, Nelson CP, Niiranen T, Nolte IM, Nutile T, Oldehinkel AJ, Oostra BA, O'Reilly PF, Org E, Padmanabhan S, Palmas W, Palotie A, Pattie A, Penninx BWJH, Perola M, Peters A, Polasek O, Pramstaller PP, Nguyen QT, Raitakari OT, Ren M, Rettig R, Rice K, Ridker PM, Ried JS, Riese H, Ripatti S, Robino A, Rose LM, Rotter JI, Rudan I, Ruggiero D, Saba Y, Sala CF, Salomaa V, Samani NJ, Sarin AP, Schmidt R, Schmidt H, Shrine N, Siscovick D, Smith AV, Snieder H, Sõber S, Sorice R, Starr JM, Stott DJ, Strachan DP, Strawbridge RJ, Sundström J, Swertz MA, Taylor KD, Teumer A, Tobin
MD, Tomaszewski M, Toniolo D, Traglia M, Trompet S, Tuomilehto J, Tzourio C, Uitterlinden AG, Vaez A, van der Most PJ, van Duijn CM, Vergnaud AC, Verwoert GC, Vitart V, Völker U, Vollenweider P, Vuckovic D, Watkins H, Wild SH, Willemsen G, Wilson JF, Wright AF, Yao J, Zemunik T, Zhang W, Attia JR, Butterworth AS, Chasman DI, Conen D, Cucca F, Danesh J, Hayward C, Howson JMM, Laakso M, Lakatta EG, Langenberg C, Melander O, Mook-Kanamori DO, Palmer CNA, Risch L, Scott RA, Scott RJ, Sever P, Spector TD, van der Harst P, Wareham NJ, Zeggini E, Levy D, Munroe PB, Newton-Cheh C, Brown MJ, Metspalu A, Hung AM, O'Donnell CJ, Edwards TL; Million Veteran Program, Psaty BM, Tzoulaki I, Barnes MR, Wain LV, Elliott P, Caulfield MJ. Publisher correction: genetic analysis of over 1 million people identifies 535 new loci associated with blood pressure traits. Nature Genetics. 2018. 50: 1755-018-0297-3.

Fehrenbach E, Northoff H. Free radicals, exercise, apoptosis, and heat shock proteins. Exercise Immunology Review. 2001. 7: 66-89.

Im SA. Patterns of left ventricular hypertrophy and gemotric remodeling in essential hypertension. Korean Circulation Journal. 1995. 25: 423-433.

Jin HS, Lee SI, Park S. Association between ITGB2 genetic polymorphisms and tuberculosis. Korean J Clin Lab Sci. 2018. 50: 118-125.

Ko B, Jin HS. MACROD2 polymorphisms are associated with hypertension in korean population. Korean J Clin Lab Sci. 2019. 51: 57-63.

Lee J, Cho HS, Kim WK. The effects of regular exercise on the expression of Bcl-2 and apoptosis in myocardium of L-NAME induced hypertensive rat. Korean Journal of Sport Science. 2006. 17: 45-54.

Levy D, Garrison RJ, Savage DD, Kannel WB, Castelli WP. Prognostic implications of echocardiographically determined left ventricular mass in the framingham heart study. The New England Journal of Medicine. 1990. 322: 1561-1566.

Li X, Pontén A, Aase K, Karlsson L, Abramsson A, Uutela M, Bäckström G, Hellström M, Boström H, Li H, Soriano P, Betsholtz C, Heldin CH, Alitalo K, Ostman A, Eriksson U. PDGF-C is a new protease-activated ligand for the PDGF alpha-receptor. Nature Cell Biology. 2000. 2: 302-309.

Oh JY. Patterns of left ventricular hypertrophy by echocardiography in coronary artery diseases. Korean Circulation Journal. 1996. 26: 473-482.

Ono T, Kawabe T, Sonta S, Okamoto T. Assignment of MARK3 
alias KP78 to human chromosome band $14 q 32.3$ by in situ hybridization. Cytogenetics and Cell Genetics. 1997. 79: 101 -102 .

Pruim RJ, Welch RP, Sanna S, Teslovich TM, Chines PS, Gliedt TP, Boehnke M, Abecasis GR, Willer CJ. LocusZoom: regional visualization of genome-wide association scan results. Bioinformatics. 2010. 26:2336-2337.

Reichek N, Devereux RB. Left ventricular hypertrophy: relationship of anatomic, echocardiographic and electrocardiographic findings. Circulation. 1981. 63: 1391-1398.

Ross R. The pathogenesis of atherosclerosis: a perspective for the 1990s. Nature. 1993. 362: 801-809.

Sullivan JM, Vander Zwaag RV, el-Zeky F, Ramanathan KB, Mirvis DM. Left ventricular hypertrophy: effect on survival. Journal of the American College of Cardiology. 1993. 22: 508 -513 .

Tuinstra CL, Rautaharju PM, Prineas RJ, Duisterhout JS. The performance of three visual coding procedures and three computer programs in classification of electrocardiograms according to the Minnesota Code. Journal of Electrocardiology. 1982. 15:
345-350.

Uutela M, Laurén J, Bergsten E, Li X, Horelli-Kuitunen N, Eriksson U, Alitalo K. Chromosomal location, exon structure, and vascular expression patterns of the human PDGFC and PDGFD genes. Circulation. 2001. 103: 2242-2247.

World Health Organization. Cardiovascular death and disability can be reduced more than 50 percent. Indian J Med Sci. 2002. 57: 117-121.

Yang J, Liu X, Bhalla K, Kim CN, Ibrado AM, Cai J, Peng TI, Jones DP, Wang X. Prevention of apoptosis by Bcl-2: release of cytochrome c from mitochondria blocked. Science. 1997. 275: 1129-1132.

https://doi.org/10.15616/BSL.2019.25.3.237

Cite this article as: Jeon TE, Jin HS. PDGFC, MARK3 and $B C L 2$ Polymorphisms are Associated with Left Ventricular Hypertrophy in Korean Population. Biomedical Science Letters. 2019. 25: 237-246. 
Supplementary Table 1. Results of the case-control association analysis between SNPs in the PDGFC, MARK3, BCL2 genes and left ventricular hypertrophy in the KARE

\begin{tabular}{|c|c|c|c|c|c|c|c|c|c|c|}
\hline \multirow{2}{*}{ Gene } & \multirow{2}{*}{ Chr } & \multirow{2}{*}{ No. } & \multirow{2}{*}{ SNP } & \multirow{2}{*}{$\mathrm{BP}$} & \multirow{2}{*}{ Function } & \multirow{2}{*}{ A1 } & \multicolumn{2}{|c|}{ MAF } & \multirow{2}{*}{ OR $(95 \% \mathrm{CI})$} & \multirow{2}{*}{$\begin{array}{l}\text { Additive } \\
P \text { value }\end{array}$} \\
\hline & & & & & & & Cases & Controls & & \\
\hline \multirow{15}{*}{$P D G F C$} & \multirow{15}{*}{4} & 1 & rs7672622 & 157925001 & Intron & $\mathrm{C}$ & 0.257 & 0.243 & $1.08(0.97 \sim 1.21)$ & 0.161 \\
\hline & & 2 & rs17035257 & 157934512 & Intron & $\mathrm{C}$ & 0.165 & 0.170 & $0.99(0.87 \sim 1.13)$ & 0.862 \\
\hline & & 3 & rs4691380 & 157939574 & Intron & $\mathrm{A}$ & 0.288 & 0.285 & $1.04(0.93 \sim 1.16)$ & 0.520 \\
\hline & & 4 & rs10517653 & 157953440 & Intron & A & 0.056 & 0.064 & $0.89(0.72 \sim 1.09)$ & 0.247 \\
\hline & & 5 & rs10033375 & 157953762 & Intron & $\mathrm{C}$ & 0.077 & 0.065 & $1.18(0.98 \sim 1.42)$ & 0.083 \\
\hline & & 6 & rs9307953 & 157968941 & Intron & $\mathrm{T}$ & 0.271 & 0.251 & $1.12(1.00 \sim 1.25)$ & $\underline{0.050}$ \\
\hline & & 7 & rs10517657 & 158005478 & Intron & A & 0.152 & 0.160 & $0.96(0.84 \sim 1.10)$ & 0.528 \\
\hline & & 8 & rs17035367 & 158005675 & Intron & $\mathrm{G}$ & 0.063 & 0.065 & $1.00(0.82 \sim 1.22)$ & 0.981 \\
\hline & & 9 & rs7662187 & 158006222 & Intron & $\mathrm{C}$ & 0.064 & 0.065 & $1.01(0.82 \sim 1.23)$ & 0.939 \\
\hline & & 10 & rs342317 & 158009437 & Intron & $\mathrm{G}$ & 0.249 & 0.243 & $1.04(0.93 \sim 1.16)$ & 0.529 \\
\hline & & 11 & rs17035387 & 158013333 & Intron & A & 0.009 & 0.012 & $0.76(0.46 \sim 1.25)$ & 0.279 \\
\hline & & 12 & rs2343116 & 158032128 & Intron & $\mathrm{G}$ & 0.110 & 0.111 & $1.01(0.87 \sim 1.18)$ & 0.864 \\
\hline & & 13 & rs10517660 & 158061846 & Intron & A & 0.382 & 0.392 & $0.96(0.86 \sim 1.06)$ & 0.380 \\
\hline & & 14 & rs6851803 & 158076643 & Intron & $\mathrm{C}$ & 0.010 & 0.012 & $0.77(0.48 \sim 1.24)$ & 0.282 \\
\hline & & 15 & rs17035464 & 158099171 & intron & $\mathrm{T}$ & 0.119 & 0.118 & $1.02(0.87 \sim 1.18)$ & 0.832 \\
\hline \multirow{18}{*}{$M A R K 3$} & \multirow{18}{*}{14} & 1 & rs6575983 & 102939602 & Upstream & $\mathrm{G}$ & 0.116 & 0.096 & $1.24(1.06 \sim 1.45)$ & $\underline{0.007}$ \\
\hline & & 2 & rs4906321 & 102948635 & Upstream & $\mathrm{T}$ & 0.137 & 0.121 & $1.15(0.99 \sim 1.33)$ & 0.063 \\
\hline & & 3 & rs2065018 & 102948940 & Upstream & $\mathrm{C}$ & 0.307 & 0.318 & $0.93(0.84 \sim 1.04)$ & 0.193 \\
\hline & & 4 & rs975892 & 102953102 & Intron & $\mathrm{T}$ & 0.454 & 0.442 & $1.03(0.93 \sim 1.14)$ & 0.565 \\
\hline & & 5 & rs17679127 & 102959844 & Intron & $\mathrm{G}$ & 0.045 & 0.034 & $1.26(0.99 \sim 1.61)$ & 0.064 \\
\hline & & 6 & rs8015723 & 102965662 & Intron & A & 0.367 & 0.359 & $1.04(0.94 \sim 1.15)$ & 0.486 \\
\hline & & 7 & rs17841064 & 102970362 & Intron & $\mathrm{G}$ & 0.456 & 0.446 & $1.02(0.93 \sim 1.13)$ & 0.633 \\
\hline & & 8 & rs6575988 & 102970580 & Intron & $\mathrm{G}$ & 0.430 & 0.424 & $1.01(0.91 \sim 1.11)$ & 0.884 \\
\hline & & 9 & rs12894275 & 102971177 & Intron & A & 0.314 & 0.325 & $0.93(0.83 \sim 1.03)$ & 0.160 \\
\hline & & 10 & rs2065015 & 102973814 & Intron & $\mathrm{G}$ & 0.311 & 0.322 & $0.93(0.84 \sim 1.04)$ & 0.188 \\
\hline & & 11 & rs17095251 & 102983535 & Intron & A & 0.115 & 0.125 & $0.87(0.75 \sim 1.01)$ & 0.069 \\
\hline & & 12 & rs17679475 & 102986711 & Intron & $\mathrm{G}$ & 0.122 & 0.103 & $1.21(1.04 \sim 1.41)$ & $\underline{0.016}$ \\
\hline & & 13 & rs 2273703 & 102987782 & Intron & $\mathrm{G}$ & 0.122 & 0.103 & $1.21(1.04 \sim 1.41)$ & $\underline{0.015}$ \\
\hline & & 14 & rs 2273702 & 102987935 & Intron & $\mathrm{C}$ & 0.439 & 0.429 & $1.02(0.92 \sim 1.12)$ & 0.708 \\
\hline & & 15 & rs10141388 & 103009432 & Intron & $\mathrm{G}$ & 0.120 & 0.102 & $1.21(1.04 \sim 1.41)$ & $\underline{0.015}$ \\
\hline & & 16 & rs3783397 & 103017042 & Intron & $\mathrm{G}$ & 0.304 & 0.317 & $0.92(0.83 \sim 1.03)$ & 0.137 \\
\hline & & 17 & rs3783398 & 103019131 & Intron & $\mathrm{C}$ & 0.305 & 0.316 & $0.93(0.84 \sim 1.04)$ & 0.196 \\
\hline & & 18 & rs9671414 & 103037052 & Intron & $\mathrm{C}$ & 0.431 & 0.422 & $1.02(0.92 \sim 1.13)$ & 0.706 \\
\hline \multirow{8}{*}{$B C L$} & \multirow{8}{*}{18} & 1 & rs10503078 & 58951168 & Intron & A & 0.399 & 0.396 & $1.02(0.92 \sim 1.12)$ & 0.715 \\
\hline & & 2 & rs4987839 & 58956729 & Intron & $\mathrm{C}$ & 0.408 & 0.410 & $0.99(0.90 \sim 1.09)$ & 0.831 \\
\hline & & 3 & rs1531697 & 58957586 & Intron & A & 0.426 & 0.424 & $1.01(0.92 \sim 1.12)$ & 0.820 \\
\hline & & 4 & rs17756073 & 58960763 & Intron & $\mathrm{G}$ & 0.116 & 0.135 & $0.84(0.72 \sim 0.98)$ & $\underline{0.022}$ \\
\hline & & 5 & rs12457831 & 58961220 & Intron & $\mathrm{C}$ & 0.392 & 0.389 & $1.01(0.92 \sim 1.12)$ & 0.836 \\
\hline & & 6 & rs1542578 & 58965895 & Intron & A & 0.458 & 0.435 & $1.09(0.99 \sim 1.20)$ & 0.088 \\
\hline & & 7 & rs17070739 & 58970363 & Intron & $\mathrm{G}$ & 0.132 & 0.156 & $0.84(0.73 \sim 0.96)$ & $\underline{0.012}$ \\
\hline & & 8 & rs4941185 & 58974534 & Intron & $\mathrm{T}$ & 0.479 & 0.456 & $1.10(1.00 \sim 1.21)$ & 0.051 \\
\hline
\end{tabular}


Supplementary Table 1. Results of the case-control association analysis between SNPs in the PDGFC, MARK3, BCL2 genes and left ventricular hypertrophy in the KARE (Continued)

\begin{tabular}{|c|c|c|c|c|c|c|c|c|c|c|}
\hline \multirow{2}{*}{ Gene } & \multirow{2}{*}{$\mathrm{Chr}$} & \multirow{2}{*}{ No. } & \multirow{2}{*}{ SNP } & \multirow{2}{*}{$\mathrm{BP}$} & \multirow{2}{*}{ Function } & \multirow{2}{*}{ A1 } & \multicolumn{2}{|c|}{ MAF } & \multirow{2}{*}{ OR $(95 \% \mathrm{CI})$} & \multirow{2}{*}{$\begin{array}{l}\text { Additive } \\
P \text { value }\end{array}$} \\
\hline & & & & & & & Cases & Controls & & \\
\hline & & 9 & rs2199937 & 58978769 & Intron & $\mathrm{C}$ & 0.476 & 0.459 & $1.08(0.98 \sim 1.19)$ & 0.136 \\
\hline & & 10 & rs7228914 & 58984206 & Intron & A & 0.498 & 0.491 & $1.05(0.95 \sim 1.16)$ & 0.338 \\
\hline & & 11 & rs4940576 & 58999619 & Intron & $\mathrm{A}$ & 0.407 & 0.409 & $1.00(0.90 \sim 1.10)$ & 0.989 \\
\hline & & 12 & rs4941187 & 59000196 & Intron & $\mathrm{C}$ & 0.409 & 0.408 & $1.01(0.91 \sim 1.12)$ & 0.868 \\
\hline & & 13 & rs899966 & 59010221 & Intron & $\mathrm{T}$ & 0.401 & 0.403 & $1.00(0.90 \sim 1.10)$ & 0.976 \\
\hline & & 14 & rs 12457700 & 59011226 & Intron & $\mathrm{T}$ & 0.399 & 0.402 & $1.00(0.90 \sim 1.10)$ & 0.955 \\
\hline & & 15 & rs 17757541 & 59030666 & Intron & $\mathrm{G}$ & 0.176 & 0.178 & $0.98(0.86 \sim 1.11)$ & 0.761 \\
\hline & & 16 & rs4987774 & 59043342 & Intron & $\mathrm{G}$ & 0.291 & 0.301 & $0.97(0.87 \sim 1.08)$ & 0.602 \\
\hline & & 17 & rs1893506 & 59044660 & Intron & $\mathrm{G}$ & 0.138 & 0.128 & $1.06(0.92 \sim 1.23)$ & 0.390 \\
\hline & & 18 & rs1775798 & 59044959 & Intron & $\mathrm{G}$ & 0.049 & 0.049 & $1.01(0.81 \sim 1.27)$ & 0.915 \\
\hline & & 19 & rs9959874 & 59045526 & Intron & A & 0.138 & 0.128 & $1.06(0.92 \sim 1.23)$ & 0.398 \\
\hline & & 20 & rs17070861 & 59057460 & Intron & $\mathrm{C}$ & 0.051 & 0.050 & $1.05(0.83 \sim 1.31)$ & 0.703 \\
\hline & & 21 & rs11152375 & 59057664 & Intron & $\mathrm{C}$ & 0.484 & 0.481 & $1.03(0.93 \sim 1.14)$ & 0.534 \\
\hline & & 22 & rs17685559 & 59061198 & Intron & A & 0.048 & 0.048 & $1.01(0.81 \sim 1.27)$ & 0.920 \\
\hline \multirow[t]{13}{*}{$B C L$} & 18 & 23 & rs10503079 & 59063346 & Intron & $\mathrm{T}$ & 0.046 & 0.049 & $0.97(0.77 \sim 1.23)$ & 0.830 \\
\hline & & 24 & rs17070904 & 59068036 & Intron & $\mathrm{T}$ & 0.061 & 0.074 & $0.82(0.68 \sim 1.00)$ & 0.052 \\
\hline & & 25 & rs7240326 & 59068331 & Intron & $\mathrm{G}$ & 0.237 & 0.229 & $1.02(0.91 \sim 1.14)$ & 0.755 \\
\hline & & 26 & rs8096380 & 59071461 & Intron & $\mathrm{G}$ & 0.332 & 0.346 & $0.97(0.87 \sim 1.08)$ & 0.564 \\
\hline & & 27 & rs7234941 & 59073831 & Intron & $\mathrm{T}$ & 0.182 & 0.173 & $1.06(0.93 \sim 1.21)$ & 0.364 \\
\hline & & 28 & rs3744951 & 59076960 & Intron & $\mathrm{G}$ & 0.047 & 0.047 & $1.01(0.80 \sim 1.27)$ & 0.931 \\
\hline & & 29 & rs12457893 & 59077141 & Intron & $\mathrm{T}$ & 0.382 & 0.386 & $0.98(0.89 \sim 1.08)$ & 0.671 \\
\hline & & 30 & rs3810031 & 59094075 & Intron & $\mathrm{G}$ & 0.238 & 0.239 & $1.01(0.90 \sim 1.13)$ & 0.933 \\
\hline & & 31 & rs8089331 & 59094686 & Intron & $\mathrm{G}$ & 0.199 & 0.200 & $0.99(0.88 \sim 1.12)$ & 0.909 \\
\hline & & 32 & rs4987724 & 59104259 & Intron & $\mathrm{T}$ & 0.020 & 0.023 & $0.82(0.58 \sim 1.15)$ & 0.251 \\
\hline & & 33 & rs1381548 & 59108376 & Intron & A & 0.338 & 0.348 & $0.95(0.85 \sim 1.05)$ & 0.290 \\
\hline & & 34 & rs4941195 & 59121016 & $\begin{array}{l}\text { Intron } \\
\text { variant, } \\
\text { synonymous } \\
\text { codon }\end{array}$ & $\mathrm{G}$ & 0.237 & 0.232 & $1.03(0.92 \sim 1.16)$ & 0.597 \\
\hline & & 35 & rs 12458289 & 59129566 & Intron & A & 0.266 & 0.260 & $1.04(0.93 \sim 1.16)$ & 0.492 \\
\hline
\end{tabular}

$P$-value $<0.05$ are indicated in bold. Abbreviaitons: SNP, single nucleotide polymorphism; BP, base pair; A1, minor allele; MAF, minor allele frequency; OR, odds ration; CI, confidence interval; KARE, Korean association resource 